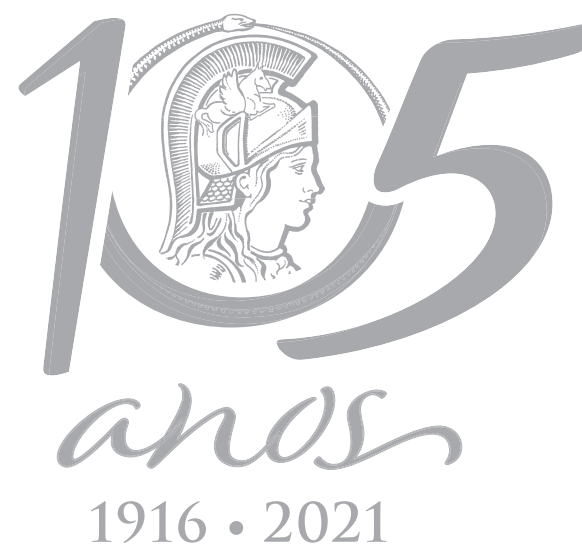

\title{
Phytochemical profile of Cespedesia spathulata leaves (Ochnaceae) and its effect on tyrosinase enzyme
}

\author{
DÉBORA R. DE OLIVEIRA, MARIANA R. DA SILVA, OTÁVIO A. CHAVES, ROSANE \\ N. CASTRO, MARCIA C.C. DE OLIVEIRA, RAIMUNDO BRAZ-FILHO \& MÁRIO G. DE \\ CARVALHO
}

\begin{abstract}
Phytochemical studies of Cespedesia spathulata (Ochnaceae) leaves using ${ }^{1} \mathrm{H}$, ${ }^{13} \mathrm{C}$ NMR, and GC-MS have led to the isolation of some metabolites identified for the first time in these species such as cathechin, epicatechin, vitexin, orientin, 6"-O-acetylvitexin, sitosterol, stigmasterol, phytol, 4,5-dihydrovomifoliol and a mixture of aliphatic methyl esters, together with ochnaflavone, which was previously isolated from this plant. The modulating activity of some fractions and compounds from Cespedesia spathulata towards tyrosinase enzyme was assayed by spectroscopic and theoretical means/ experiments. The dichloromethane fraction $\left(133 \mu \mathrm{g} \mathrm{mL} \mathrm{L}^{-1}\right)$ and ochnaflavone (333 $\left.\mu \mathrm{M}\right)$ inhibited tyrosinase activity by $20 \%$ and $2.0 \%$, respectively, whereas the ethyl acetate fraction $\left(666 \mu \mathrm{g} \mathrm{mL} \mathrm{L}^{-1}\right.$ ) and \pm catechins (catechin and epicatechin - $800 \mu \mathrm{M}$ ) activated it by $104 \%$ and $384 \%$, respectively. Quantum chemical calculations suggested that catechin and epicatechin are better activators than L-DOPA by interacting with CU (II) ions. Molecular docking results suggested that hydrogen bonding and hydrophobic interactions are the main binding forces between each tyrosinase activator and the amino acid residues inside the active protein binding pocket.
\end{abstract}

Key words: Cespedesia spathulata, molecular docking, Ochnaceae, Tyrosinase.

\section{INTRODUCTION}

Cespedesia spathulata (Ruiz \& Pav.) Planch., Ochnaceae (Sastre 1995), is recognized from its spatulate leaves with oboval and lax inflorescences (Chacon et al. 2011). According to Lobstein et al. (2004), C. spathulata biosynthesizes flavonoids and biflavonoids such as ochnaflavone and 7"-O-methylochnaflavone. The biosynthesis of biflavonoids is in accordance with the profile of the species belonging to the Ochnaceae family, mainly in the Luxemburgieae tribe (Bandi et al. 2012, Fidelis et al. 2014). In this phytochemical study we confirmed the presence of the biflavonoid ochnaflavone, previously identified in Cespedesia species (Lobstein et al. 2004), in addition to three flavones and two catechins.

The term "melanin" describes a group of high-molecular-mass polymers associated with a wide variety of functions in different organisms (Langfelder et al. 2003). The polymerization reactions that synthesize melanin occur in cells named melanocytes and the tyrosinase enzyme (EC 1.14.18.1) is the main protein responsible for the conversion of the tyrosine substrate to melanin by melanocytes. Tyrosinase first oxidizes the tyrosine substrate to dihydroxyphenylalanine (L-DOPA), and subsequently oxidizes L-DOPA to L-DOPAquinone. Frequent changes in skin color 
occur in mammals in the form of increased skin coloration (hyperpigmentation) or a loss of tone (hypopigmentation). Inhibition of catalytic tyrosinase activity can decrease melanin synthesis, resulting in a hypopigmentation effect. Hypopigmentation can be caused by diseases, injury, burns or other traumas to the skin. Treatment options are often limited and are based on topical medications that might help, although they have shown poor efficacy even when used for a long time. Thus, it is necessary to find new compounds that would be effective in the treatment of hypopigmentation of the human skin (Lee et al. 2016, Guan et al. 2008).

According to Chang (2009), several phenolic compounds show tyrosinase inhibitory activity. The inhibitory mode of some flavonoids is usually of a competitive inhibitory type in relation to oxidation of L-DOPA by tyrosinase enzyme and the 3-hydroxy-4-keto moiety of the structure is responsible for acting in copper chelation (Chang 2009). In addition, catechin derivatives obtained from Camellia sinensis (green tea) have depigmentation activity by inhibiting the action of tyrosinase (Sato \& Toriyama 2009). Thus, it is justified to assess these properties with original partitions and isolated metabolites identified in Cespedesia spathulata that belong to this class of compounds. On this basis, the objective of the present study was to assess the phytochemical profile and pharmacological aspects of Cespedesia spathulata. We report here the extraction, fractionation (by chromatographic techniques) and identification of compounds (by GC-MS, 1D, 2D ${ }^{1} \mathrm{H}$ and ${ }^{13} \mathrm{C} N M R$, and mass spectrometry) isolated from extracts of $C$. spathulata leaves. Some fractions and isolated compounds were assayed for tyrosinase activity by in vitro analysis and then correlated with theoretical calculations by quantum chemical and molecular docking analysis.

\section{MATERIALS AND METHODS}

\section{Plant Material}

Cespedesia spathulata leaves were collected in Jardim Botânico - Rio de Janeiro/Brazil, in September 2016 and identified by Dr. Marcus A. Nadruz Coelho. A voucher specimen (RB 664411) was deposited in the Herbarium of Jardim Botânico - Rio de Janeiro/Brazil.

\section{Instrumentation and Reagents}

The ${ }^{1} \mathrm{H}$ and ${ }^{13} \mathrm{C}$ uni- (1D) and two-dimensional (2D) nuclear magnetic resonance spectra were obtained with a Bruker spectrometer [400 or $500 \mathrm{MHz}\left({ }^{1} \mathrm{H}\right), 100$ or $125 \mathrm{MHz}\left({ }^{13} \mathrm{C}\right)$ ] using $\mathrm{CDCl}_{3}$, DMSO- $d_{6}$, or methanol- $d_{4}$ as solvents, and tetramethylsilane (TMS) as an internal standard for chemical shift reference.

The chromatograms and low-resolution mass spectra were recorded with a chromatograph coupled to a quadrupole mass spectrometer under the following conditions: electron impact ionization at $70 \mathrm{eV}$ with a split mode injector, injection temperature of $250{ }^{\circ} \mathrm{C}$, flow of $1 \mathrm{ml} . \mathrm{min}^{-1}$, and gradient elution from 60 ${ }^{\circ} \mathrm{C}$ to $290{ }^{\circ} \mathrm{C}$ within a $40 \mathrm{~min}$ period.

Electrospray ionization-high-resolution spectra were measured with a quadrupole/ time-of-flight instrument (microTOF II, Bruker Daltonics Billerica, MA), only used for its contribution to substance identification $\mathbf{2 1}$.

High Performance Liquid Chromatography (HPLC) analyses were performed using a Shimadzu LC 6AD and 10AD photodiode detector (PDA), UV 300-600 nm, Luna Phenomenex C18 column $(25.0 \times 4.6 \times 5.0 \mathrm{~mm})$. Open column chromatography (CC) was carried out with silica gel (Sigma Aldrich $0.05-0.20 \mathrm{~mm}$ ) and Sephadex LH-20 (Sigma Aldrich - USA); Normal phase aluminum-backed analytical TLC (Sorbent silica gel plates W/UV 254) with visualization under 
254 and $366 \mathrm{~nm}$ UV and chemical development with sulfuric vanillin solution.

Biological assays were performed with mushroom tyrosinase, EDTA, L-DOPA, dimethylsulfoxide (DMSO) and phosphate buffer solution (PBS), pH 6.8, purchased from Sigma Aldrich - Brazil.

\section{Extraction and isolation of the compounds}

The dried and powered leaves of Cespedesia spathulata (CS) $(1.55 \mathrm{~kg})$ were exhaustively extracted by maceration with $6 \mathrm{~L} n$-hexane and $12 \mathrm{~L}$ methanol: $\mathrm{H}_{2} \mathrm{O}$ (90:10) solution at room temperature (ca $298 \mathrm{~K}$ ). The solvent of the solutions was removed by distillation under vacuum to yield the residues $n$-hexane $(H)$ and hydromethanolic solution $\left(\mathrm{MH}_{2} \mathrm{O}\right)$ extracts (CSH: $21.77 \mathrm{~g}$ and $\mathrm{CSMH}_{2} \mathrm{O}: 109.87 \mathrm{~g}$ ), respectively. Part of the hydromethanolic extracts $\left(\mathrm{CSMH}_{2} \mathrm{O}\right.$, $22.00 \mathrm{~g}$ ) was solubilized with the $\mathrm{MeOH}: \mathrm{H}_{2} \mathrm{O}$ (8:2) solution and subjected to successive extractions with $n$-hexane, dichloromethane and ethyl acetate. This processing yielded the n-hexane $\left(\mathrm{CSMH}_{2} \mathrm{O}-\mathrm{H}, 4.82 \mathrm{~g}\right)$, dichloromethane $\left(\mathrm{CSMH}_{2} \mathrm{O}-\mathrm{D}, 4.10 \mathrm{~g}\right)$, and ethyl acetate fractions $\left(\mathrm{CSMH}_{2} \mathrm{O}-\mathrm{A}, 12.84 \mathrm{~g}\right)$ which were selected for chromatographic fractionation.

The $\mathrm{CSMH}_{2} \mathrm{O}-\mathrm{H}$ fraction (4.00 g) was fractionated by CC on silica gel (80.7 g; $37.0 \mathrm{x}$ $3.5 \mathrm{~cm}$ ) using binary mixtures of $n$-hexane, dichloromethane, ethyl acetate and methanol as the eluent. The solvent polarity was increased gradually, yielding 75 fractions of $125 \mathrm{~mL}$ each, which were analyzed by silica gel plate TLC and recombined into groups of fractions. The subfractions 10-11 (0.1941 g) and 18-20 (0.4822 g), obtained with the hexane and dichloromethane solutions (90:10, and 60:40, respectively) were analyzed by GC-MS, ${ }^{1} \mathrm{H}$ and ${ }^{13} \mathrm{C}$ NMR (500/ 125 $\mathrm{MHz}$ ) spectroscopy (using $\mathrm{CDCl}_{3}$ as solvent). These analyses led to the identification of compounds $\mathbf{1}$ to $\mathbf{1 3}$ (Table I) in a mixture, and $\mathbf{1 4}$, respectively. The position of the double bond in the unsaturated methyl ester (5, Table I) was defined by mass spectrum analyses of the dithiomethyl ether derivative (see discussion) (Carvalho et al. 2000). The group containing fractions 24-26 (0.0929 g), obtained with hexane and dichloromethane (50:50), was purified through sephadex-LH20 eluted with dichloromethane and methanol (30:70). The same analyses and solvent as mentioned above were used in the study of this group of fractions, allowing the identification of compounds $\mathbf{1 5}$ and 16.

Fraction $\mathrm{CSMH}_{2} \mathrm{O}-\mathrm{D}(3.10 \mathrm{~g})$ was fractionated on CC silica gel $(76.9 \mathrm{~g} ; 35.0 \times 3.5 \mathrm{~cm})$ and eluted with binary mixtures of hexane, dichloromethane and ethyl acetate by increasing the polarity gradients. About 36 fractions, $125 \mathrm{~mL}$ each, were collected and analyzed by silica gel plate TLC and recombined into groups of fractions. Subfractions 11-12 (0.1085 g), obtained with dichloromethane and ethyl acetate (60:40) as eluents, were subjected to purification on Sephadex LH2O and eluted with chloroform and methanol (30:70). Compound $\mathbf{1 7}$ was identified by ${ }^{1} \mathrm{H},{ }^{13} \mathrm{C}$ NMR $(500 / 125 \mathrm{MHz})$ plus 2D experiments (COSY, NOESY, HSQC and HMBC) using $\mathrm{CD}_{3} \mathrm{OD}$ as solvent. Subfractions 20-24 (0.3786 g), obtained by ethyl acetate and methanol (90:10) as eluents, were pooled and purified through SephadexLH20, using $\mathrm{CHCl}_{3}: \mathrm{CH}_{3} \mathrm{OH}(30: 70)$ as eluent. In this purification, compound $\mathbf{1 8}$ was identified by ${ }^{1} \mathrm{H},{ }^{13} \mathrm{C}$ NMR (500/ $125 \mathrm{MHz}$ ) plus 2D experiments (COSY, NOEDIF, HSQC and HMBC) using DMSO- $d_{6}$ as solvent.

The $\mathrm{CSMH}_{2} \mathrm{O}-\mathrm{A}$ residue $(7.20 \mathrm{~g})$ was fractionated by CC on silica gel ( $84.4 \mathrm{~g} ; 45.0 \mathrm{x}$ $6.0 \mathrm{~cm}$ ) and eluted initially with dichloromethane, ethyl acetate and methanol to increase the polarity. About 70 fractions, $125 \mathrm{~mL}$ each, were obtained, which were analyzed by plate TLC. The group of fractions 24-26 (0.0368 g), obtained by 
dichloromethane and ethyl acetate (40:60) as eluents, was filtered through Sephadex LH2O using methanol as eluent. Sixteen fractions were obtained from this process, 11-15 of which were reunited $(0.0304 \mathrm{~g})$ and analyzed by ${ }^{1} \mathrm{H}$ and ${ }^{13} \mathrm{C}$ NMR $(400 / 100 \mathrm{MHz})$ plus 2D experiments (COSY, HSQC and HMBC, using $\mathrm{CD}_{3} \mathrm{OD}$ as solvent), and compounds $\mathbf{1 9}$ and $\mathbf{2 0}$ were identified in the mixture. Fraction 35 (2.0734 g), obtained with ethyl acetate as eluent, was filtered through Sephadex LH20 eluted with methanol. Fractions 20-23 (0.0508 g) were selected from this process and submitted to semi-preparative high performance liquid chromatography (HPLCUV) fractionation, yielding $X$ fractions. A direct transfer of the analytical HPLC-DAD conditions to a semi-preparative HPLC-UV using the same stationary phase provided a rational and efficient fractionation. The fraction was purified isocratically using a flow rate of $4.0 \mathrm{~mL} \mathrm{~min}{ }^{-1}$ with the following mobile phase system: (solvent A) $1 \%$ acetic acid water and (solvent $B$ ) methanol (55:45, v/v). The analysis was carried out at room temperature using a C18 reversed-phase column (250 mm × 10 mm i.d, $5.0 \mu \mathrm{m}$, Luna Phenomenex) and detection was performed by UV at $205 \mathrm{~nm}$. In this procedure, compound $\mathbf{2 1}$ was isolated and identified by analysis of ${ }^{1} \mathrm{H}$ and ${ }^{13} \mathrm{C}$ NMR (500/ $100 \mathrm{MHz}$ ) spectra and 2D experiments (COSY, $\mathrm{HSQC}$ and $\mathrm{HMBC}$ ) using $\mathrm{CD}_{3} \mathrm{OD}$ as solvent, and mass spectrum. The set of fractions 29-31 (0.0324 g), also obtained from the refractionation of fraction 35, was analyzed by ${ }^{1} \mathrm{H}$ and ${ }^{13} \mathrm{C}$ NMR (500/ $100 \mathrm{MHz}$ ) and 2D experiments (COSY, HSQC and HMBC) using DMSO- $d_{6}$ as solvent. The analysis of these spectra allowed the identification of vitexin (22) and orientin (23), in a mixture.

\section{Tyrosinase enzyme activity assay}

In the present study, each sample was examined for its ability to interfere with tyrosinase activity - using L-DOPA as substrate - according to the assay protocol described by Soares et al. (2017). Each sample [dichloromethane $\left(\mathrm{CSMH}_{2} \mathrm{O}-\mathrm{D}\right)$ and ethyl acetate fractions $\left(\mathrm{CSMH}_{2} \mathrm{O}-\mathrm{A}\right)$ from C. spathulata leaves] was prepared in 10

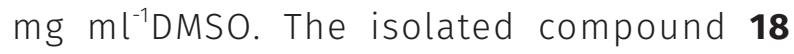
(ochnaflavone) and the mixture of catechin 19 and epichatechin $\mathbf{2 0}$ ( \pm catechins) were also prepared in $10 \mathrm{mmol} \mathrm{ml}^{-1}$ DMSO for evaluation. Different aliquots of the solution were added to the reaction medium containing tyrosinase (50-70 units), EDTA (0.022 $\left.\mathrm{mmol} \mathrm{L}^{-1}\right), \mathrm{L}-\mathrm{DOPA}$ $\left(0.17 \mathrm{mmol} \mathrm{L}^{-1}\right)$, and PBS (50 mmol L-1 $\mathrm{pH} \mathrm{6.8)} \mathrm{at}$ room temperature. The reaction process was analyed after 30 minutes with a Shimadzu UVVIS spectrophotometer, model Mini 1240, Japan, at $475 \mathrm{~nm}$. Percent activation or inhibition was calculated according to Equation 1 (Soares et al. 2017):

$\%$ inhibition or activation $=\left\{\left[\left(B_{30}-B_{0}\right)-\left(A_{30}-\right.\right.\right.$ $\left.\left.\left.A m_{0}\right)\right] /\left(B_{30}-B_{0}\right)\right\} \times 100$

where $B_{0}=$ absorbance of L-DOPA + tyrosinase at $t=0 \mathrm{~min}, B_{30}=$ absorbance of L-DOPA + tyrosinase at $t=30 \mathrm{~min}, A_{0}=$ absorbance of L-DOPA + tyrosinase + inhibitor/activator at $t=0$ min, and $A_{30}=$ absorbance of L-DOPA + tyrosinase + inhibitor/activator at $t=30 \mathrm{~min}$.

\section{Theoretical calculations}

The L-DOPA, catechin and epicatechin structures were built and energy-minimized by Density Functional Theory (DFT) calculations, with the Becke-3-Lee Yang Parr (B3LYP) potential and 6-31G* basis set, available in the Spartan'14 software (Soares et al. 2017, Hehre 2003). The theoretical molecular descriptors: highest occupied molecular orbital (HOMO), lowest unoccupied molecular orbital (LUMO) and electrostatic potential map were calculated from the conformer(L-DOPA, catechin and epicatechin) with the lowest energy geometry obtained by Spartan'14 software (DFT-B3LYP-6-31G*). Since 
there are different conformation possibilities for L-DOPA, catechin, and epicatechin, the lowest energy geometry was basically obtained by Conformer Distribution calculation with a geometry cycle of 1,000 (DFT/B3LYP/6-31G*) via Spartan'14 software in the gas phase.

The crystallographic structure of mushroom Agaricus bisporus tyrosinase was obtained from the Protein Data Bank (access code 2Y9X) (Ismaya et al. 2011). In solution, mushroom tyrosinase is a complex of two $\mathrm{H}$-chains (heavy) and two L-chains (light), and only the H-chains contain the binuclear copper site (responsible for tyrosinase activity). In order to propose a molecular explanation for the experimental tyrosinase data, a $10 \AA$ radius-spherical domain around the binuclear copper site (location: 2Y9X_A_AC1_4) was defined for the molecular docking calculations for the conformer (L-DOPA, catechin and epicatechin) with the lowest energy previously obtained by Spartan'14 software. Chain D was defined for the molecular docking studies due to the best results obtained in the redocking studies with the cocrystallized ligand tropolone in the 2Y9X structure (Ismaya et al. 2011). Molecular docking studies were performed with GOLD 5.2 software (CCDC, Cambridge Crystallographic Data Centre). Hydrogen atoms were added to the enzyme structure according to the data inferred by the GOLD 5.2 software on the ionization and tautomeric states and the number of genetic operations (crossover, migration, mutation) in each docking run was set to 100,000 (Lopes et al. 2018). Docking runs were carried out for the biomacromolecule, allowing complete flexibility for the ligands. Since the GOLD 5.2 software optimizes hydrogen bond geometries by rotating hydroxyl and amino groups of amino acid side chains (for the case of proteins), around the protein's cavity, some amino acid side chains were allowed to stay flexible during the docking runs. This was done because the flexibility of amino acid side chains could enable a better fit of L-DOPA, catechin and epicatechin into the sites. The scoring function used to perform the tyrosinase study was GoldScore - the best scoring function identified for tropolone in the redocking study (Soares et al. 2017). The figures for the best molecular docking pose to the tyrosinase/ligand were generated with the PyMOL DeLano Scientific LLC software (DeLano 2002).

\section{RESULTS AND DISCUSSION}

\section{Identification of compounds}

The interpretation of the ${ }^{1} \mathrm{H}$ and ${ }^{13} \mathrm{C}$ NMR spectra of the $\mathrm{CSMH}_{2} \mathrm{O}-\mathrm{H}, 10-11,18-20$, and 24-26 fractions, along with the GC-MS spectra analysis and comparison with library equipment, permitted the identification of the first 16 substances (Figure 1). The sequence of aliphatic methyl esters (1 to $\mathbf{1 3}$, Table I) was identified in $\mathrm{CSMH}_{2} \mathrm{O}-\mathrm{H}$ 10-11. Analysis of these fractions by ${ }^{1} \mathrm{H}$ and ${ }^{13} \mathrm{C}$ NMR revealed that the compounds were compatible with aliphatic methyl esters, showing NMR signals at $\delta_{\mathrm{C}} 174.05 \mathrm{ppm}, \delta_{\mathrm{CH} 3} 51.14$ and 13.88, and $\delta_{\mathrm{CH}_{2}} 33.86-22.50 \mathrm{ppm}$ in the ${ }^{13} \mathrm{C} \mathrm{NMR}$ spectra; The ${ }^{1} \mathrm{H}$ NMR spectrum revealed a $\delta_{H} 3.63$ $\left(\mathrm{s}, \mathrm{OCH}_{3}\right), 1.25\left(\mathrm{~m}\right.$, coalesced $\left.\mathrm{CH}_{2}\right), 2.27$ and 1.58 of protons $\alpha$ and $\beta$ to carbonyl, and a terminal methyl group at $\delta_{H} 0.85(t)$ (see Supplementary Material, Table SI). The double bond of $\mathbf{5}$ was confirmed by weak signals of $\delta_{\mathrm{CH}} 129.73$ and 129.48, and weak signal $\delta_{H} 1.95(\mathrm{~m})$ and $5.31(\mathrm{~s}$, that is according to the $Z$ double bond, common in natural fatty esters) in the spectra. The value of $\delta_{\mathrm{CH} 2}$ at $22.5 \mathrm{ppm}$ can be attributed to an allylic methylene carbon of $\mathbf{5}$. The chromatogram obtained by GC-MS (EI) revealed the presence of 15 components and the mass spectra of each component were compared to the spectra of the NIST 11.0 library of the equipment. These data permitted the identification of 13 aliphatic 
methyl esters. The observed similarity and the percentage of each identified substance within the fraction are described in Table I. The same procedure described by Carvalho et al. (2000) were used to define the position of the double bond in compound $\mathbf{5}$. The dithiomethyl ether derivative was prepared by treatment of $\mathbf{5}$ with dithiomethyldisulphide and subjected to analysis by EIMS. The main peaks at $m / z 390\left(\mathrm{M}^{+}\right.$, 15\%), $217\left(\left[\mathrm{C}_{11} \mathrm{H}_{21} \mathrm{O}_{2} \mathrm{~S}\right]^{+}, 100 \%\right)$, and $173\left(\left[\mathrm{C}_{10} \mathrm{H}_{21} \mathrm{~S}\right]^{+}\right.$, $90 \%)$, among others, were used to confirm the presence of the double bond at C-9.

Phytol (14) was identified in $\mathrm{CSMH}_{2} \mathrm{O}-\mathrm{H}$ 1820 by the analysis of the ${ }^{1} \mathrm{H}$ NMR spectrum that showed signals of $\delta_{H}$ at $5.36(H-2, m), \delta_{H} 4.10(H-$ $1, d, J=6.65 \mathrm{~Hz}), \delta_{H} 2.48(\mathrm{H}-4, m), \delta_{H} 2.1(\mathrm{H}-5, m)$, the $\mathrm{H}-16,17,18,19$, and 20 represented by signals between 0.9 and 1.6 ppm (see Table SII). These data, including the ${ }^{13} \mathrm{C}$ NMR data, agree with those reported by DeLano (2002). The mass spectrum obtained for $\mathbf{1 4}$ showed $98 \%$ similarity when compared to data from the NIST 11.0 library, also confirming this proposal.
Sitosterol and stigmasterol $(\mathbf{1 5}+\mathbf{1 6})$ were identified by ${ }^{1} \mathrm{H}$ and ${ }^{13} \mathrm{C}$ NMR spectra analysis of fraction $\mathrm{CSMH}_{2} \mathrm{O}-\mathrm{H}$ 24-26. ${ }^{1} \mathrm{H}$ NMR presented signals at $\delta_{H} 5.37$ (brs, H-6 of $\mathbf{1 5}$ and 16), $5.19(\mathrm{~m}$, $\mathrm{H}-22, \mathbf{1 6})$ and $5.05(\mathrm{~m}, \mathrm{H}-23, \mathbf{1 6}), 3.54$ ( $\mathrm{m}, \mathrm{H}-3$ of both 15 and 16), 2.0 and 2.3 (of allylic proton of 15 and 16), besides signals at 0.87-1.3 of methyl groups of steroids (see Table SIII). These data, together carbon-13 spectra analysis and in comparison with those published by Goodman et al. (1973), confirm the mixture of sitosterol and stigmasterol $(\mathbf{1 5}+\mathbf{1 6}$, Figure $\mathbf{1})$.

The fractions selected after the chromatographic assays were applied to the $\mathrm{CSMH}_{2} \mathrm{O}-\mathrm{D}$ fraction was subjected to spectroscopic analysis, which permitted the identification of two substances, a terpenoid (17), and a biflavonoid (18) (Figure 1).

The known terpene 4,5-dihydrovomifoliol (17) was identified by the interpretation of the ${ }^{1} \mathrm{H}$ and ${ }^{13} \mathrm{C}$ NMR spectra and was compared with literature data. The ${ }^{1} \mathrm{H}$ NMR spectrum presented $\delta_{H}$ at $5.87(\mathrm{H}-8, d d, J=15.7 ; 6.3 \mathrm{~Hz})$ and $5.84(\mathrm{H}-7$,

Table I. Compounds identified by GC-MS in the $\mathrm{CSMH}_{2} \mathrm{O}-\mathrm{H} 10-11$ fraction.

\begin{tabular}{|c|c|c|c|c|c|}
\hline & Tret (min) & Compounds & $\mathbf{m} / \mathbf{z}$ & Similarity & Percentage \\
\hline $\mathbf{1}$ & 15.033 & Methyl tetradecanoate & 242 & 96 & 1.22 \\
\hline $\mathbf{2}$ & 16.117 & Methyl pentadecanoate & 256 & 97 & 3.00 \\
\hline $\mathbf{3}$ & 17.242 & Methyl palmitate & 270 & 97 & 37.94 \\
\hline $\mathbf{4}$ & 18.142 & Methyl heptadecanoate & 284 & 96 & 7.50 \\
\hline $\mathbf{5}$ & 18.867 & (Z) Methyl 9-octadecenoate & 296 & 95 & 13.07 \\
\hline $\mathbf{6}$ & 19.100 & Methyl stearate & 298 & 96 & 13.73 \\
\hline $\mathbf{7}$ & 19.967 & Methyl nonadecanoate & 312 & 97 & 2.96 \\
\hline $\mathbf{8}$ & 20.833 & Methyl eicosanoate & 326 & 94 & 3.31 \\
\hline $\mathbf{9}$ & 22.467 & Methyl docosanoate & 354 & 93 & 3.24 \\
\hline $\mathbf{1 0}$ & 23.233 & Methyl tricosanoate & 368 & 94 & 5.68 \\
\hline $\mathbf{1 1}$ & 23.975 & Methyl tetracosanoate & 382 & 93 & 3.54 \\
\hline $\mathbf{1 2}$ & 24.742 & Methyl pentacosanoate & 396 & 910 & 93 \\
\hline $\mathbf{1 3}$ & 25.617 & Methyl hexacosanoate & & 93 & \\
\hline
\end{tabular}


$d, J=15.7 \mathrm{~Hz}$ ) of a trans double bond, 4.35 of carbinolic and allylic proton $(\mathrm{H}-9$, qui, $J=6.3$ ), signals of two methylene groups: $\mathrm{CH}_{2}-2[2.89(d$, $J=13.5)$, and $1.84(d d, J=13.5 ; 2.2)], \mathrm{CH}_{2}-4[(2.46$, $\mathrm{t}, J=13.2)$ and $(2.13(\mathrm{brd}, J=13.2 \mathrm{~Hz})$ ], a multiplet at 2.29 of one proton $(\mathrm{H}-5)$, besides signals of four methyl groups at $1.29(d, J=6,3, H-10), 1.23$ $(\mathrm{H}-11, \mathrm{~s}), 0.94(\mathrm{H}-12, \mathrm{~s})$ and $0.92(d, 6.6 \mathrm{~Hz}, \mathrm{H}-13)$. The HMQC spectrum presented signals of ${ }^{1} \mathrm{~J}_{\mathrm{HC}}$ of these protons with carbons, respectively, $135.23(\mathrm{CH}-8), 130.87(\mathrm{CH}-7), 67.67(\mathrm{CH}-9), 51.09$ $\left(\mathrm{CH}_{2}-2\right), 44.78\left(\mathrm{CH}_{2}-4\right), 35,59(\mathrm{CH}-5), 22.29,23.61$, 23.56, $14.97\left(\mathrm{CH}_{3}-10,11,12,13\right.$, respectively), that were observed in the ${ }^{13} \mathrm{C}$ NMR spectrum together with the quaternary carbons 213.50 (C-3), 76.48 (C-6) and 42.48 (C-1). Additional analysis of 2D NMR experiments (NOESY and HMBC), (see Table SIV) and mass spectra analysis $[\mathrm{m} / \mathrm{z} 226$ $\left(\mathrm{M}^{+}, \mathrm{C}_{13} \mathrm{H}_{22} \mathrm{O}_{3}\right.$ ] confirmed the structure of $\mathbf{1 7}$ as 4,5-dihydrovomifoliol (Figure 1) described by Galbraith \& Horn (1972).

The biflavonoid, ochnaflavone, (18) was identified by analysis of $1 \mathrm{D}$ and $2 \mathrm{D}{ }^{1} \mathrm{H}$ and ${ }^{13} \mathrm{C}$ NMR spectra. The $1 \mathrm{D}$ and $2 \mathrm{D}{ }^{1} \mathrm{H}$ NMR spectra showed signals compatible with two protons systems, $A A^{\prime} B B^{\prime}$ and $A B C$, corresponding to the $B$ ring of each flavone unit. A pair of doublets at $\delta_{H}$ 7.02 and $8.04\left(J=8.5 \mathrm{~Hz}\right.$ ) was assigned to $\mathrm{H}-2^{\prime \prime} / 6^{\prime \prime}$ and $H-3^{\prime \prime} / 5^{\prime \prime}$, and the signals at $\delta_{H} 7.87(H-2, s)$, $7.89(\mathrm{H}-6, d, J=8.8 \mathrm{~Hz})$ and $7.13\left(\mathrm{H}-5^{\prime}, d, J=8.8 \mathrm{~Hz}\right)$, representing the $A B C$ system. Other observed signals justify the proposal of two flavone units, one singlet at $\delta_{H} 6.18$ corresponding to $\mathrm{H}-3$ and $\mathrm{H}-3$ ", and two doublets, $\delta_{H} 6.18(J=3.75 \mathrm{~Hz})$ of $\mathrm{H}-6$ and $\mathrm{H}-6^{\prime \prime}$, and $\delta_{H} 6.48(J=3.75 \mathrm{~Hz})$ of $\mathrm{H}-8$ and $\mathrm{H}-8$ ". Two additional singlets at 12.94 and 12.87 of chelated hydroxyls are compatible with the proposed biflavonone. These data, allied to the ${ }^{13} \mathrm{C}$ NMR spectrum, besides HMQC, HMBC analysis (see Table SV), and comparison with literature values (Son et al. 1992), confirmed the proposed structure of $\mathbf{1 8}$ as ochnaflavone. This compound has already been identified in C. spathulata, as well as in other Ochanaceae species such as Ochna punila, O. obtusata, O. beddomei (Lobstein et al. 2004) and Luxemburgia octandra (Lu \& Foo 1999).

The mixture of flavan-3-ols, cathechin and epicathechin (19 + 20, Figure 1) was identified as the component of a fraction analyzed by ${ }^{1} \mathrm{H}$ and ${ }^{13} \mathrm{C}$ NMR spectra. Two doublets at $\delta_{H} 4.57(\mathrm{H}-2$, $\left.d_{,} J=9,4 \mathrm{~Hz}, \mathbf{1 9}\right)$ and $4.81(\mathrm{H}-2, \mathrm{brs}, \mathbf{2 0})$ and two multiplets at $\delta_{H} 4.17$ (narrow, 20) and 3.98 (wide, 19) were attributed to $\mathrm{H}-3$ of each one, respectively. The appearance of the signals is in accordance with the relative stereochemistry of the protons in both catechins. Two pairs of signals, presented by the ${ }^{1} \mathrm{H} x^{1} \mathrm{H}$-COSY spectrum, led to the identification of the chemical shift of $\mathrm{H}-4$ of 19 and 20: $\delta_{H} 2.50(H-4 a x, d d, J=16.08$ and $8.0 \mathrm{~Hz}$, ), and $2.87(\mathrm{H}-4 \mathrm{eq}, d m, J=16.08 \mathrm{~Hz}$, ) of 19, and $\delta_{H} 2.75(H-4 a x, d m, J=16.8 \mathrm{~Hz}$,$) , and$ $2.83(\mathrm{H}-4 \mathrm{eq}, \mathrm{dm}, J=16.80 \mathrm{~Hz})$ of $\mathbf{2 0}$. The protons $\mathrm{H}-6$ and $\mathrm{H}-8$ protons of both compounds are presented by signals at $\delta_{H} 5.93(\mathrm{~m})$ and $5.86(\mathrm{~m})$. The signals at $6.97 / 6.84,6.75 / 6.73$ and 6.75/6.79 can be attributed to protons $\mathrm{H}-2, \mathrm{H}-5^{\prime}$ and $\mathrm{H}-6^{\prime}$, respectively, of ring $\mathrm{B}$ of $\mathbf{1 9}$ and $\mathbf{2 0}$. The ${ }^{13} \mathrm{C}$ NMR presented pairs of signals of $\delta_{{ }^{\prime}} \delta_{C H}$ and $\delta_{\mathrm{CH} 2}$ compatible with the mixture that was confirmed by the analysis of HMQC and HMBC spectra (see Table SVI). These data were compared to those published by Lu \& Foo (1999). These compounds have been previously identified in Ouratea ferruginea, Ouratea hexasperma and Ouratea sp. (Fidelis et al. 2012, Monache et al. 1967).

6"-O-acetylvitexin (21) was identified by signals observed in ${ }^{1} \mathrm{H}$ and ${ }^{13} \mathrm{C}$ NMR, including $\mathrm{HMQC}$ and $\mathrm{HMBC}$ experiments $\left(\mathrm{MeOH}-\mathrm{d}_{4}\right)$. These analyses permitted the identification of each proton and of carbon-13 data $\delta_{H} / \delta_{C}$. The $\delta_{H} /$ $\delta_{C H} 8.05\left(H-2^{\prime} / \sigma^{\prime}, d, J=8.8 \mathrm{~Hz}\right) / 130.29$ and 6.96 $\left(H-3^{\prime} / 5^{\prime}, d, J=8.8 \mathrm{~Hz}\right) / 117.12$, correspond to the AA'BB' system; $6.61(H-3, s) / 103.78$, and 6.21 
$(\mathrm{H}-6, \mathrm{~s}) /$ 99.12. Besides the acetyl group 1.73 (s, $3 \mathrm{H}-8) / 20.69\left(\mathrm{CH}_{3}\right) / 172.08(\mathrm{C})$, a sugar unit was identified by $\delta_{H} / \delta_{C H} 5.55(H-2 ", m) / 74.21 ; 5.08(H-$ 1", $d, J=10,05 \mathrm{~Hz}) / 73.14 ; 3.99$ and $3.85\left(\mathrm{H}-6^{\prime \prime}, \mathrm{m}\right) /$ $63.05\left(\mathrm{CH}_{2}\right) ; \delta_{H} 3.72(\mathrm{H}-3$ " and 4", m)/ 77.90 and 72,36; $\delta_{H} 3.52\left(H-5^{\prime \prime}, d, J=8.85 \mathrm{~Hz}\right) /$ 83.28. The HMBC spectrum confirmed the position of sugar at C-8 (see Table SVII). The HRMS spectrum, in negative mode, confirmed this proposal by peaks at $\mathrm{m} / \mathrm{z}$ $473.1012\left[100 \%, \mathrm{C}_{23} \mathrm{H}_{21} \mathrm{O}_{11}(\mathrm{M}-\mathrm{H})\right.$, calc. 473.1089], 413.0807 (80\%, M-H-60), 292.0389 (50\%). These NMR data were compared with those published by Oh \& Kim (1993) and were used to confirm the structure of 21.

The other two flavones in the mixture, vitexin (22) and orientin (23), whose ${ }^{1} \mathrm{H} N M R$ $\left(\mathrm{MeOH}-d_{4}\right)$ presented chemical shifts at $\delta_{H} 7.95$ $\left(H-2^{\prime} / 6^{\prime}, \mathrm{d}, J=8.0 \mathrm{~Hz}\right)$ and $\delta_{H} 6.87\left(\mathrm{H}-3^{\prime} / 5^{\prime}, \mathrm{d}, J=8.0\right.$ $\mathrm{Hz}$ ) corresponding to the $A A^{\prime} B^{\prime} B^{\prime}$ system of $\mathbf{2 2}$, and the signals at $\delta_{H} 7.36\left(\mathrm{H}-2^{\prime}, \mathrm{sl}\right), 6,73\left(\mathrm{H}-5^{\prime}, \mathrm{d}\right.$, $J=8.5 \mathrm{~Hz})$ and $7.44(d d)$ were attributed to $A B C$ system of 23. The singlets at $\delta_{\mu} 6.56$ and 5.92 were assigned to $\mathrm{H}-3$ and $\mathrm{H}-6$ of compound 22. The singlets at $\delta_{H} 6.42$ and 5.97 were assigned to $\mathrm{H}-3$ and $\mathrm{H}-6$ of compound 23. The ${ }^{1} \mathrm{H}$ NMR data attributed to $\mathbf{2 2}$ were similar to those of $\mathbf{2 1}$. Some signals of glucose units, between 4.72 and 3.25 ppm, were observed. The ${ }^{13} \mathrm{C}$ NMR spectrum showed chemical shifts values compatible with C-glycoside flavonoids, $\mathbf{2 2}$ and $\mathbf{2 3}$. The glucose position at $\mathrm{C}-8$ was defined by the information set observed, the exact chemical shift for the substituted C-8 (104.70 ppm) and the absence of the singlet corresponding to $\mathrm{H}-8$ (see Table SVIII). These data were compared with those obtained by Krafczyk \& Glomb (2008) which were used to confirm both structures for $\mathbf{2 2}$ and $2 \mathbf{3}$. Previously publications have already identified vitexin and orientin in Ouratea hexasperma (Suzart et al. 2012), vitexin in Ochna integerrima (Reutrakul et al. 2007) and 6"-O-acetylvitexin in Ouratea gilgiana (Fidelis et al. 2014).

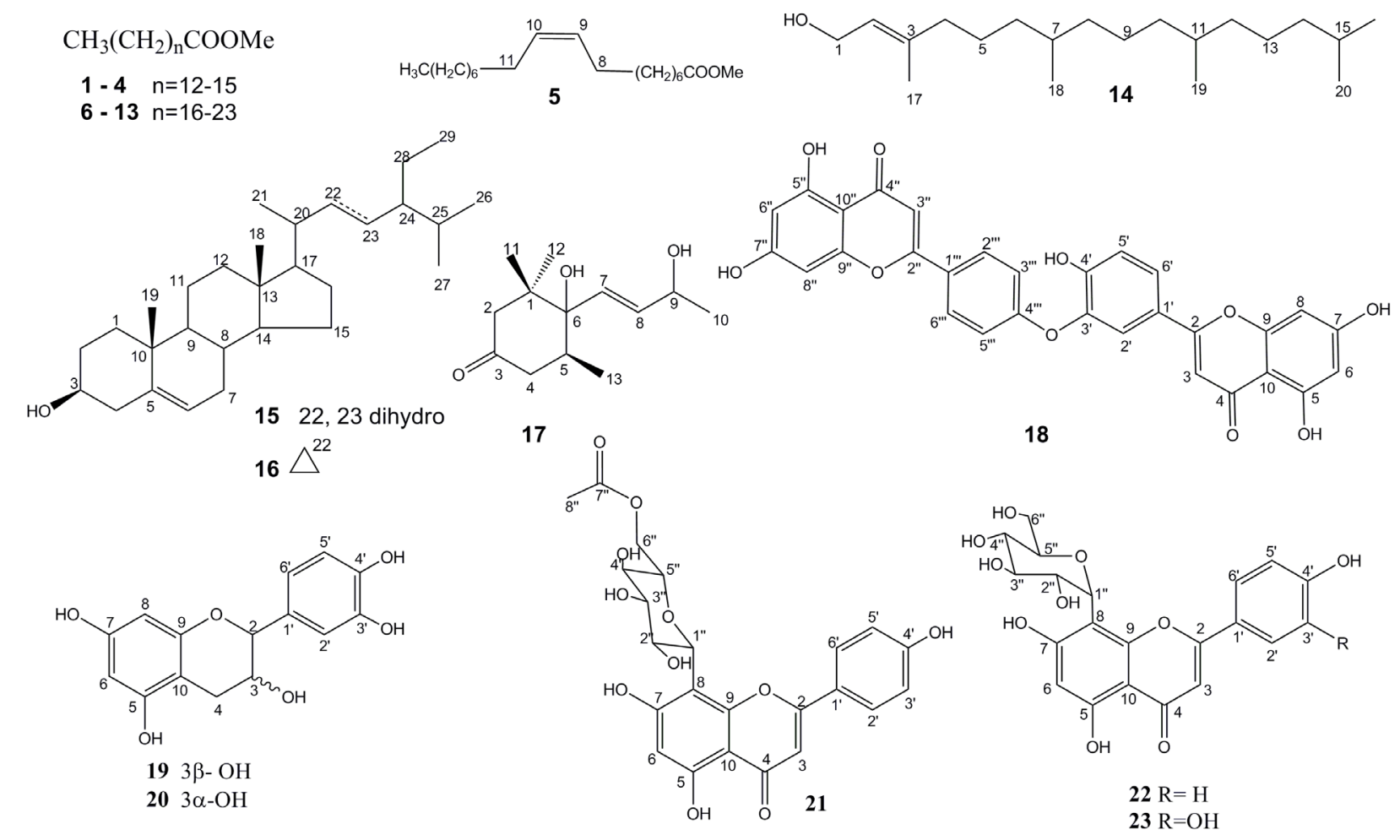

Figure 1. Compounds isolated from Cespedesia spathulata. 


\section{Tyrosinase activity assay}

Polyphenolic compounds are biosynthesized as secondary metabolites in higher plants and present some important biological activities, from protection against UV radiations to inhibition of different enzymes. Some flavonoids, e.g. kaempferol, quercetin and morin, show inhibitory activity on tyrosinase activity, while others, e.g. \pm cathechins, can act as cofactors or substrates for tyrosinase (Sato \& Toriyama 2009). Considering the activity of phenolic compounds on tyrosinase, the screening of the potential tyrosinase regulator was evaluated from some extracts and isolated flavonoids obtained from c. spathulata leaves. The highest doses tested depended on the solubility of each sample in the aqueous medium.

Both the dichloromethane extract $(133 \mu \mathrm{g} \mathrm{mL}$ ${ }^{1}$ ) and compound $\mathbf{1 8}(333 \mu \mathrm{M})$ inhibited tyrosinase activity by $20 \%$ and $2.0 \%$, respectively. On the other hand, the ethyl acetate extract $(666 \mu \mathrm{g} \mathrm{mL}$ $\left.{ }^{1}\right), \pm$ catechins (catechin and epicatechin - 800 $\mu \mathrm{M}$ ) increased tyrosinase activity by $104 \%$ and $384 \%$, respectively. As can be seen in Figure 2, \pm catechins can significantly activate tyrosinase in a dose-dependent manner by acting as cofactors or substrates for the enzyme. If the catechins acted as cofactors, the in vitro product of the reaction was dopaquinone, but if the catechins acted as a substrate for the enzyme, the in vitro reaction products were the compounds obtained by catechin oxidation. Therefore, the effect of catechin interaction with tyrosinase was corroborated in the study on the inhibitory effect of catechins on melanogenesis by Sato \& Thoriyama (2009). Thus, the ethyl acetate extract of C. spathulata (rich in catechins) and only the mix of catechins could be used as a potential treatment for hypopigmentation disease caused by the failed action of tyrosinase.

Since the variations of the Michaelis constant $\left(\mathrm{K}_{m}\right.$ - concentration of the substrate, in which the reaction rate corresponds to half the maximum speed) and $V_{m}$ values (maximum velocity in the presence of an inhibitor) for tyrosinase activators have not been described in the literature, an experiment similar to the Lineweaver-Bruk method was carried out in order to determine the inhibitory mechanism of \pm catechins (substrate) in the presence L-DOPA (inhibitor) (Figure 3, Table II).

The graph in Figure 3 and the results shown in Table II revealed that the kinetic parameters $\mathrm{K}_{m}$ decreased, $\mathrm{V}_{\max }$ increased, and the $\mathrm{K}_{m} / \mathrm{V}_{m}$ ratio decreased in the presence of L-DOPA, showing that the mechanism of tyrosinase inhibition by L-DOPA is competitive.

Therefore, an increase in the catalytic activity of the enzyme in the presence of low concentrations of compounds in addition

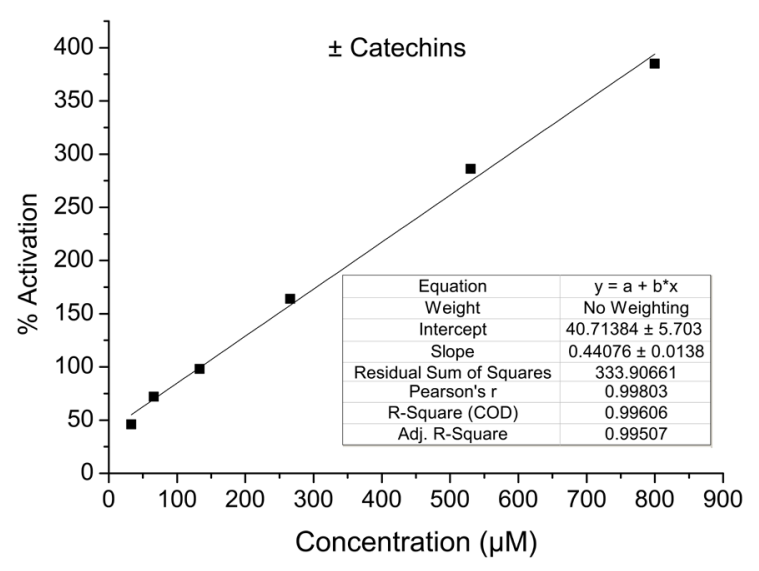

Figure 2. Dose-dependent activation effects on tyrosinase by \pm catechins (catechin and epicatechin).

Table II. Michaelis constant and maximum speed for tyrosinase activity in the presence of \pm catechins.

\begin{tabular}{|c|c|c|c|}
\hline [L-DOPA in $\boldsymbol{\mu M}$ ] & $\mathbf{K}_{\boldsymbol{m}}$ & $\mathbf{V}_{\boldsymbol{m}}$ & $\mathbf{K}_{\boldsymbol{m}} / \mathbf{V}_{\boldsymbol{m}}$ \\
\hline 0 & 220 & 16.8 & 11.9 \\
\hline 167 & 45.4 & 24.8 & 3.6 \\
\hline 233 & 37.0 & 26.4 & 1.4 \\
\hline 333 & 25.6 & 29.2 & 0.87 \\
\hline
\end{tabular}




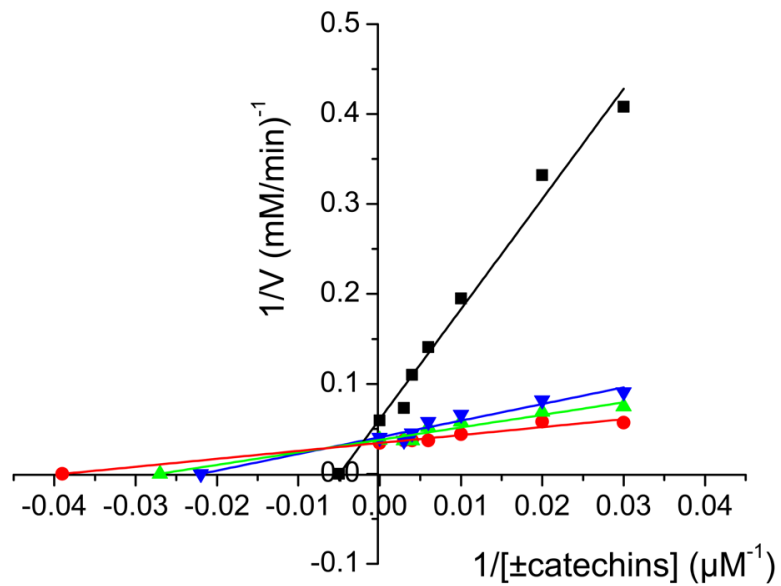

Figure 3. Experiment similar to the LineweaverBurk method for the evaluation of $\mathrm{K}_{m}$ and $\mathrm{V}_{m}$ in the tyrosinase assays. The substrate was a mixture of catechin and epicatechin, and concentrations of L-DOPA for each plot were $0(\square), 167(\nabla), 233(\Delta)$ and $333(\bullet) \mu \mathrm{M}$.

to an affinity for their active site indicates a competitive effect of these compounds on the active site of the enzyme. Molecular docking calculations were then carried out in order to offer an atomic view for the affinity of \pm catechins (catechin and epicatechin) and L-DOPA toward the active protein binding pocket of tyrosinase.

\section{Theoretical analysis of the tyrosinase/ligand interaction}

Since tyrosinase is a dicopper-containing enzyme, it is expected that potential tyrosinase activators will show a high binding affinity for Cu (II) ions. Therefore, the highest occupied molecular orbital (HOMO) from each ligand probably will interact with the lowest unoccupied molecular orbital (LUMO) from Cu (II) ions. The calculated HOMO values for L-DOPA, catechin and epicatechin were $-5.90 \mathrm{eV},-5.51 \mathrm{eV}$ and $-5.46 \mathrm{eV}$, respectively (Figure 4). Since catechin and epicatechin have higher HOMO energy values than L-DOPA, it is suggested that these compounds have a better interaction with $\mathrm{Cu}$ (II) ions (Kim \& Uyama 2005). In addition, the electrostatic charge value of one of the hydroxyl group in the aromatic ring of the catechin and epicatechin structure is larger (-0.557 and -0.564 , respectively) than that of the hydroxyl group present in the L-DOPA structure (-0.540 - Figure 4), supporting the hypothesis that catechin and epicatechin have a better interaction with $\mathrm{Cu}$ (II) ions (Chaves et al. 2018).

In order to explain tyrosinase activity by the L-DOPA, catechin and epicatechin activators at the atomic level, as well as to suggest the key residues that are important for the proteinligand interaction, a molecular docking study was carried out. The theoretical score of each pose was calculated as the negative of the sum of a series of energy terms involved in the proteinligand interaction process, so that the more positive the score, the better the interaction. The highest docking score values for L-DOPA, catechin and epicatechin were 51.9, 54.8, and 54.2 (dimensionless), suggesting that catechin and epicatechin can be better accommodated inside the protein pocket than L-DOPA. The molecular docking results suggested that all studied compounds can be fitted inside the protein binding site, and both are close to the binuclear copper site (the site responsible for tyrosinase activity). One of the hydroxyl groups from the aromatic ring moiety of each ligand is the main chemical group responsible for the complexation with $\mathrm{Cu}$ (II) ions, with an average distance value of $2.10 \AA-2.40 \AA$ (Figure 5a). The HOMO orbital was also localized in the same hydroxyl group (phenol) of the ligand structure, in agreement with the chemical approximation showing that HOMO density regions can interact preferentially with low electron density regions (in this case $\mathrm{Cu}(\mathrm{II})$ - Figure 4).

The molecular docking results suggested hydrophobic interactions and hydrogen bonding as the main intermolecular forces involved in the tyrosinase:ligand interaction. In the case of 

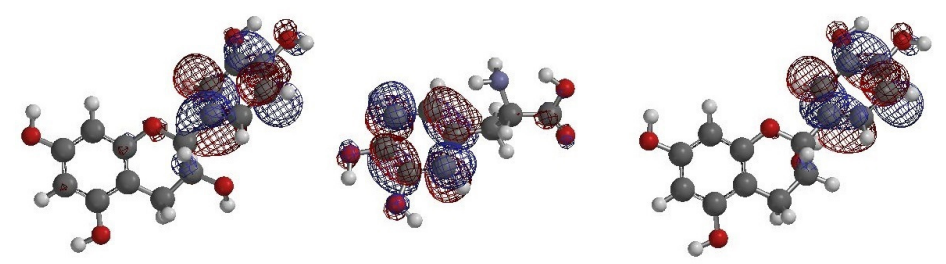

$E_{\text {LUMo }}=-0.17 \mathrm{eV}$

$E_{\text {LUMo }}=-0.19 \mathrm{eV}$

$E_{\text {Lumo }}=-0.15 \mathrm{eV}$

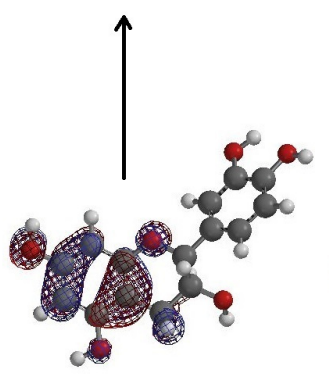

$E_{\text {номо }}=-5.51 \mathrm{eV}$

Catechin

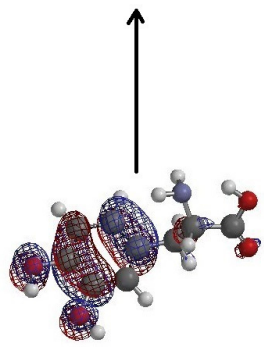

$\mathrm{E}_{\text {номо }}=-5.90 \mathrm{eV}$

L-DOPA

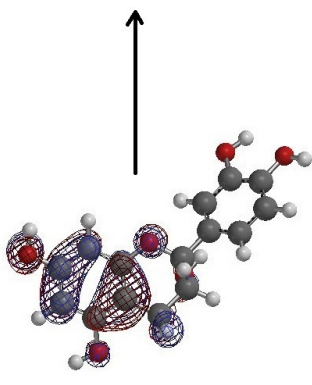

$\mathrm{E}_{\text {номо }}=-5.46 \mathrm{eV}$

Epicatechin

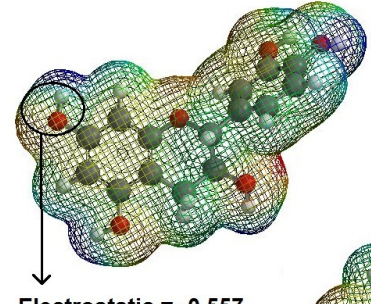

Electrostatic $=\mathbf{- 0 . 5 5 7}$ Catechin

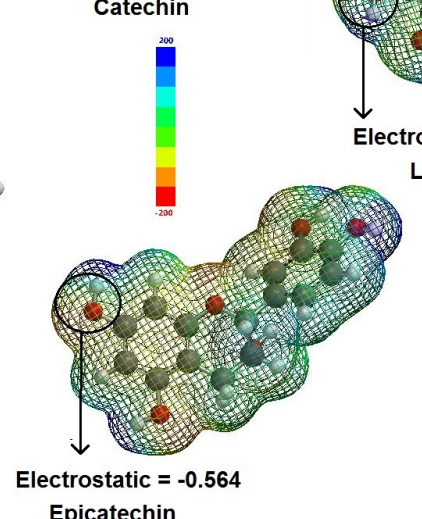

Epicatechin

Figure 4. Theoretical HOMO-LUMO and electrostatic potential map (from the ground-state calculations at the DFT/ B3LYP/-6-31G* level - unit in kJ/mol) for catechin, L-DOPA and epicatechin.

tyrosinase:L-DOPA (Figure 5b), the oxygen from the carboxyl group of the ligand structure is a potential acceptor of hydrogen bonding with the amide group of the Asn-152 residue, within a distance of $3.50 \AA$. On the other hand, the hydrogen from the amino group of the same ligand is a potential donor for hydrogen bonding with the peptidic $\mathrm{C}=\mathrm{O}$ oxygen of the Asn -152 residue, within a distance of $2.20 \AA$. Hydrophobic interactions were also detected between L-DOPA and the His-155, Phe-156, Val-172 and Phe-181 residues.

Figure $5 c$ illustrates the overlap between the best score pose for tyrosinase: catechin/ epicatechin. The oxygen from peptidic $\mathrm{C}=\mathrm{O}$ of the Met-169 and Gly-170 residues shows that these residues are potential acceptors of hydrogen bonding with two hydroxyl groups of the ligand structure within a distance of 1.60 and $1.80 \AA$, respectively. Hydrophobic interactions were also detected between the ligand structure at the Val140, His-155, Phe-156, Val-172, Ala-175 and Phe-181 residues. Overall, the molecular docking results suggested that catechin and epicatechin have better HOMO energy and hydroxyl electrostatic values than L-DOPA for interaction with $\mathrm{Cu}$ (II) ions. In addition, catechin and epicatechin can also be accommodated inside the active binding site of tyrosinase, interacting with more types of amino acid residues than L-DOPA.

\section{CONCLUSION}

The current phytochemical studies revealed the presence of different secondary metabolites in C. spathulata leaves. The metabolites characterized here in the extract from the leaves of this species have not been reported in previous studies of this plant, except for ochnaflavone. The present results contribute to knowledge about the chemosystematics of the genus and show similarity to other Ochnaceae species. The tyrosinase assays demonstrated 

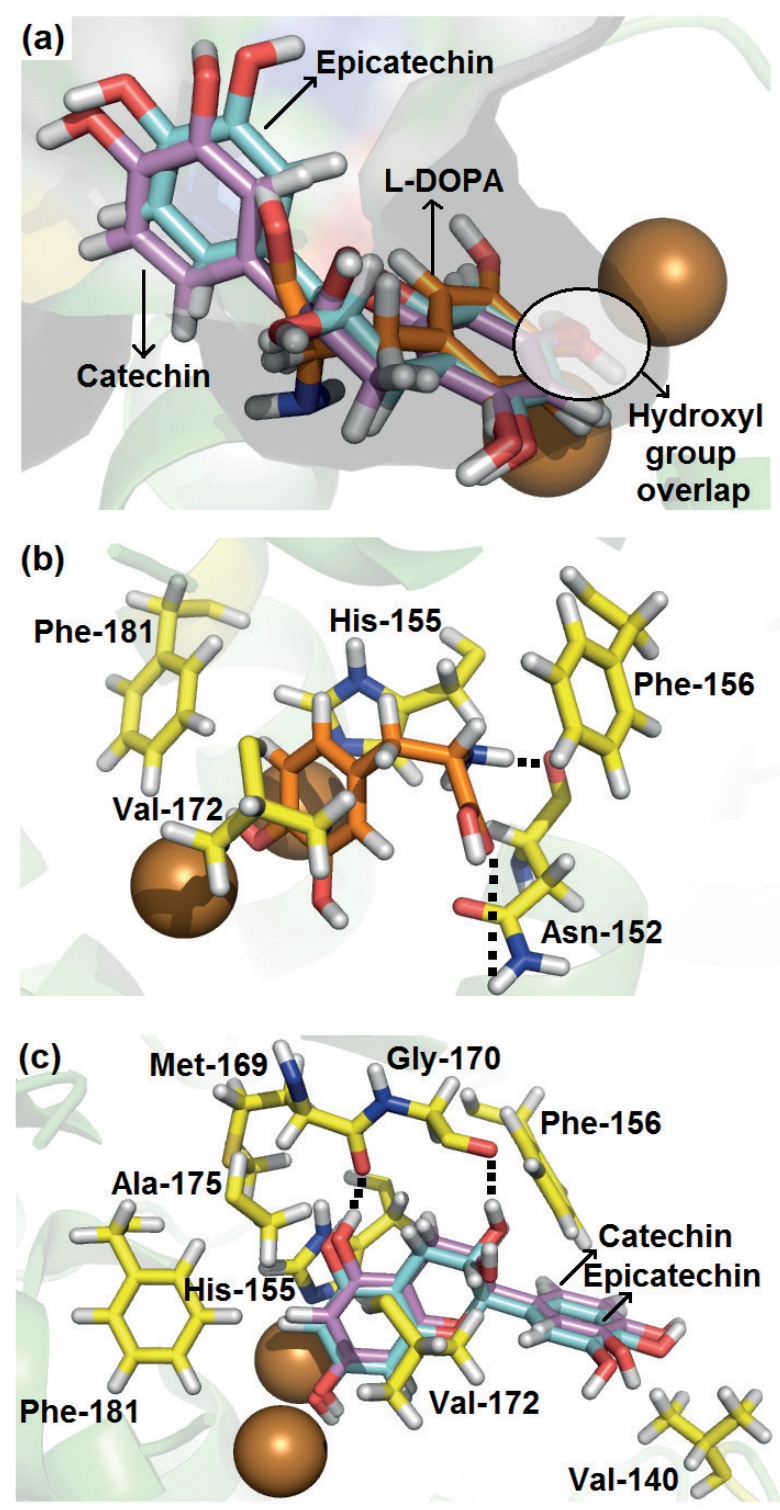

Figure 5. (a) Overlap between three potential tyrosinase activators interacting with $\mathrm{Cu}$ (II) ions. (b) Best score pose for tyrosinase:L-DOPA. (c) Overlap between the best score pose for tyrosinase:catechin/ epicatechin. Selected amino acids residues, L-DOPA, catechin and epicatechin are represented as sticks in yellow, orange, violet and cyan, respectively. Copper ions ( $\mathrm{Cu}$ (II) are represented as spheres in brown. Black dots represent interaction via hydrogen bonding. Hydrogen: white; oxygen: red; nitrogen: dark blue, and sulfur: goldenrod. that the ethyl acetate fraction of C. spathulata, rich in catechin and epicatechin, can increase the enzyme activity. The result obtained for catechin and epicatechin and the ethyl acetate fraction diverge from the suppressive behavior shown by other catechin-derived metabolites evaluated under the action of tyrosinade (Sato \& Toriyama 2009). Since catechin/epicatechin showed a better molecular docking profile and quantum chemical properties than L-DOPA. It is an evidence that the ethyl acetate extract from $C$. spathulata leaves can be explored as a potential treatment for hypopigmentation disease.

\section{Acknowledgments}

This research was supported by the following Brazilian funding agencies: Fundação Carlos Chagas Filho de Amparo à Pesquisa do Estado do Rio de Janeiro (FAPERJ), Coordenação de Aperfeiçoamento de Pessoal de Nivel Superior (CAPES), Conselho Nacional de Desenvolvimento Científico e Tecnológico (CNPq), Processo: 308580/20150 . Special thanks are due to Jardim Botânico do Rio de Janeiro/Brazil for ceding the collected species.

\section{REFERENCES}

BANDI AKR, LEE DU, TIH RG, GUNASEKAR D \& BODO B. 2012. Phytochemical and biological studies of Ochna species. Chem Biodivers 9(2): 251-271.

CARVALHO MG DE, OLIVEIRA MCC DE \& WERLE AA. 2000. Chemical Constituents from Luxemburgia nobilis (EICHL). J Brazilian Chem Soc 11(3): 232-236.

CHACON RG, YAMAMOTO K \& CAVALCANTI B. 2011. Ouratea lancifolia R. G. Chacon \& K. Yamam. (Ochnaceae), uma nova espécie do Cerrado, Brasil. Braz J Bot 34 (4): 603-605.

CHANG T. 2009. An Updated Review of Tyrosinase Inhibitors. Int J Mol Sci 10: 2440-2475.

CHAVES OA, SANTOS MRL, DE OLIVEIRA MCC, SANT'ANNA CMR, FERREIRA RC \& ECHEVARRIA A. 2018. Synthesis, tyrosinase inhibition and transportation behavior of novel $\beta$ enamino thiosemicarbazide derivatives by human serum albumin. J Mol Liq 254: 280-290.

DELANO WL. 2002. PyMOL User's Guide. DeLano Scientific LLC: San Carlos, CA, USA, p. 38-45. 
FIDELIS QC, CASTRO RN, GUILHON GMSP, RODRIGUES ST, DE SALLES CMC, DE SALLES JB \& DE CARVALHO MG. 2012. Flavonoids and other compounds from Ouratea ferruginea (Ochnaceae) as anticancer and chemopreventive agents. Molecules 17(7): 7989-8000.

FIDELIS QC, RIBEIRO TAN, ARAÚJO MF \& DE CARVALHO MG. 2014. Ouratea genus: Chemical and pharmacological aspects. Brazilian J Pharmacogn 24(1): 1-19.

GALBRAITH MN \& HORN DHS. 1972. Structures of the Natural Products Blumenols A, B, and C. J Chem Soc Chem Commun 3: 113-114.

GOODMAN RA, OLDFIELD E \& ALLERHAND A. 1973. Assignments in the Natural-Abundance Carbon-13 Nuclear Magnetic Resonance Spectrum of Chlorophyll a and a Study of Segmental Motion. J Am Chem Soc 328(6): 7553-7558.

GUAN S, SU W, WANG N, LI P \& WANG Y. 2008. A Potent Tyrosinase Activator from Radix Polygoni multiflori and its Melanogenesis Stimulatory Effect in B16 Melanoma Cells. Phyther Res 660-663.

HEHRE WJ. 2003. A Guide to Molecular Mechanics and Quantum Chemical Calculations. Wavefunction, Inc., Irvine: USA, p. 21-54.

ISMAYA WT, ROZEBOOM HJ, WEIJN A, MES JJ, FUSETTI F, WICHERS HJ \& DIJKSTRA BW. 2011. Crystal Structure of Agaricus bisporus Mushroom Tyrosinase: Identity. Biochemistry 50: 5477-5486.

KIM YJ \& UYAMA H. 2005. Tyrosinase inhibitors from natural and synthetic sources: Structure, inhibition mechanism and perspective for the future. Cell Mol Life Sci 62(15): 1707-1723.

KRAFCZYK N \& GLOMB MA. 2008. Caracterization of Phenolic Compound in Rooibis Tea. J Agric Food Chem 56(9): 3371.

LANGFELDER K, STREIBEL M, JAHN B, HAASE G \& BRAKHAGE AA. 2003. Biosynthesis of fungal melanins and their importance for human pathogenic fungi. Fungal Genet Biol 38: 143-158.

LEE SY, BAEK N \& NAM TG. 2016. Natural, semisynthetic and synthetic tyrosinase inhibitors. J Enzyme Inhib Med Chem 31(1): 1-13.

LOBSTEIN A, WENIGER B, UM BH, VONTHRON C, ALZATE F \& ANTON R. 2004. Polyphenols from Cespedesia spathulata and Cespedesia macrophylla (Ochnaceae). Biochem Syst Ecol 32(2): 229-231.

LOPES ND, CHAVES OA, OLIVEIRA MCC DE, SANT'ANNA CMR, SOUSA-PEREIRA D, NETTO-FERREIRA JC \& ECHEVARRIA A. 2018. International Journal of Biological Macromolecules derivatives: Synthesis, tyrosinase inhibition evaluation and HSA binding study PMI-1 PMI-2 PMI-3 PMI-4 PMI-5. Int J Biol Macromol 112: 1062-1072.

LU Y \& FOO YL. 1999. The polyphenol constituents of grape pomace. Food Chem 65(1): 1-8.

MONACHE FD, D'ALBUQUERQUE IL, FERRARI F \& MARINI-BETTOLO GB. 1967. New proanthocyanidin dimer from Ouratea. Annali Chim 57: 1364-1371.

OH IS \& KIM IH. 1993. Pharmaco-Constituents of Crataegus pinnatifida var. psilosa Leaves (I), The Constituents from Ether Fraction. Yakhak Hoeji 37(5): 476-482.

REUTRAKUL $V$, NINGNUEK N, POHMAKOTR M, YOOSOOK C, NASPASWAD C, KASISIT J, SANTISUK T \& TUCHINDA P. 2007. Anti HIV-1 Flavonoid Glycosides from Ochna integerrima. Planta Med 73: 683-688.

SASTRE C. 1995. Ochnaceae. In: Stannard BL, Harvey YB and Harley RM (Eds). Flora of the Pico das Almas: Chapada Diamantina-Bahia, Brazil. Kew: Royal Botanic Gardens, p. 519-522.

SATO K \& TORIYAMA M. 2009. Depigmenting Effect of Catechins. Molecules 14: 4425-4432.

SOARES MA, ALMEIDA MA, MARINS-GOULART C, CHAVES OA, ECHEVARRIA A \& OLIVEIRA MCC DE. 2017. Bioorganic \& Medicinal Chemistry Letters Thiosemicarbazones as inhibitors of tyrosinase enzyme. Bioorg Med Chem Lett 27(15): 3546-3550.

SON KH, PARK JO, CHUNG KC, CHANG HW, KIM HP, KIM JS \& KANG SS. 1992. Flavonoids from the Aerial Parts of Lonicera japonica. Arch Pharm Res 15(4): 365-370.

SUZART LR, DE CARVALHO MG, CAVATTI LC \& KAPLAN MAC. 2012. Chemical constituents from the inflorescences of Ouratea hexasperma. Chem Nat Compd 48(3): 472-473.

\section{SUPPLEMENTARY MATERIAL}

\section{Tables SI-SVIII with NMR data for all substances identified.}

\begin{abstract}
How to cite:
DE OLIVEIRA DR, DA SILVA MR, CHAVES OA, CASTRO RN, DE OLIVEIRA MCC, BRAZ-FILHO R \& DE CARVALHO MG. 2021. Phytochemical profile of Cespedesia spathulata leaves (Ochnaceae) and its effect on tyrosinase enzyme. An Acad Bras Cienc 93: e20200443. DOI 10.1590/00013765202120200443.
\end{abstract}

Manuscript received on March 30, 2020;

accepted for publication on August 14, 2020 


\section{DÉBORA R. DE OLIVEIRA ${ }^{1}$}

https://orcid.org/0000-0002-5379-3214

\section{MARIANA R. DA SILVA}

https://orcid.org/0000-0003-1658-3880

\section{OTAVIO A. CHAVES ${ }^{1,2}$}

https://orcid.org/0000-0001-6211-7659

\section{ROSANE N. CASTRO ${ }^{1}$}

https://orcid.org/0000-0001-8983-3786

\section{MARCIA C.C. DE OLIVEIRA ${ }^{1}$}

https://orcid.org/0000-0002-0923-0254

\section{RAIMUNDO BRAZ-FILHO ${ }^{1}$}

https://orcid.org/0000-0001-7217-3494

\section{MÁRIO G. DE CARVALHO ${ }^{1}$}

https://orcid.org/0000-0001-5805-734X

IInstituto de Química, Universidade Federal Rural do Rio de Janeiro, Departamento de Química Orgânica, BR 465, Km 07, 23890-000 Seropédica, RJ, Brazil

${ }^{2}$ Instituto Oswaldo Cruz (IOC), Fundação Oswaldo Cruz (Fiocruz), Laboratório de Imunofarmacologia, Av. Brasil 4365, Manguinhos, 21040-360, Rio de Janeiro, RJ, Brazil

Correspondence to: Débora R. de Oliveira

E-mail:deboraolv@gmail.com

\section{Author contributions}

Débora R. de Oliveira and Mariana R. da Silva performed the fractionation of the extracts and chromatographic analyses and elucidated the structures; Marcia C. C. de Oliveira was responsible for planning and carrying out the biological assays; Rosane N. Castro contributed to HPLC analysis. Otávio A. Chaves was responsible for theoretical calculations. Raimundo Braz Filho and Mário G. de Carvalho contributed to the design and implementation of the research, the analysis of the results and manuscript writing/editing.

\section{(cc) BY}

